This item was submitted to Loughborough's Research Repository by the author.

Items in Figshare are protected by copyright, with all rights reserved, unless otherwise indicated.

\title{
Effect of team rank and player classification on activity profiles of elite wheelchair rugby players
}

\section{PLEASE CITE THE PUBLISHED VERSION}

http://dx.doi.org/10.1080/02640414.2015.1028087

\section{PUBLISHER}

(c) Human Kinetics

\section{VERSION}

AM (Accepted Manuscript)

\section{PUBLISHER STATEMENT}

This work is made available according to the conditions of the Creative Commons Attribution-NonCommercialNoDerivatives 4.0 International (CC BY-NC-ND 4.0) licence. Full details of this licence are available at: https://creativecommons.org/licenses/by-nc-nd/4.0/

\section{LICENCE}

CC BY-NC-ND 4.0

\section{REPOSITORY RECORD}

Rhodes, James, Barry Mason, Laurie A. Malone, and Vicky Goosey-Tolfrey. 2015. "Effect of Team Rank and Player Classification on Activity Profiles of Elite Wheelchair Rugby Players". Loughborough University. https://hdl.handle.net/2134/17084. 
1 Title: Effect of team rank and player classification on activity profiles of elite wheelchair 2 rugby players

3 Running Head: Influence of team rank in wheelchair rugby

4 Keywords: Paralympic sports, performance, player tracking, mobility 


\section{Abstract}

2 The aim of the current study was to establish which indicators of mobility are associated with

3 successful wheelchair rugby performance and determine whether these indicators differed

4 across classification. Data were collected from 11 international teams during 30 matches (353

5 match observations) using a radio-frequency based, indoor tracking system across two

6 tournaments. Players $(n=111)$ were first grouped by team rank as determined by their

7 International Wheelchair Rugby Federation (IWRF) world ranking (LOW, MID, HIGH) and

8 then into one of four groups based on their IWRF classification: group I (0.5), II (1.0-1.5), III

9 (2.0-2.5), IV (3.0-3.5). The volume of activity (relative distance and mean speed), peak speed, 10 and time spent within classification-specific arbitrary speed zones were calculated for each

11 individual. Although no differences were identified in the volume of activity, playing time 12 was significantly reduced in LOW (34:51 \pm 8:35) compared to MID (48:54 \pm 0:51) and 13 HIGH (45:38 \pm 9:53), which was further supported by the greater number of substitutions 14 performed by LOW. HIGH achieved greater peak speeds (3.55 $\left.\pm 0.40 \mathrm{~m} \cdot \mathrm{s}^{-1}\right)$ than LOW $(3.27$ $\left.15 \pm 0.42 \mathrm{~m} \cdot \mathrm{s}^{-1}\right)$ and MID $\left(3.45 \pm 0.41 \mathrm{~m} \cdot \mathrm{s}^{-1}\right)$. Peak speed was further shown to be 16 classification-dependent ( $P \leq 0.005$ ), whereby HIGH groups III and IV players achieved 17 greater peak speeds than LOW and MID. The time spent performing high-intensity activities 18 was also greater in HIGH compared to LOW and MID, whilst further influenced by 19 classification $(P \leq 0.0005)$. To conclude, peak speed and the ability to perform a greater 20 number of high-intensity activities were associated with successful performance in 21 wheelchair rugby. 


\section{Introduction}

2 Wheelchair rugby is an intermittent, court-based team sport characterised by frequent short3 term high-intensity demands superimposed on a background of aerobic activity. It consists of 44 x 8-minute quarters, played on an indoor wooden sprung surface (15 m x $28 \mathrm{~m}$ ). The game5 clock is started once the ball is in-play and regulations restrict a team to a total of $40 \mathrm{~s}$ to 6 score otherwise they concede possession. Participating athletes generally have one of the 7 following conditions: spinal cord injury at the level of their cervical vertebrae, multiple amputations, polio, neurological disorders such as cerebral palsy and some forms of muscular dystrophy (Goosey-Tolfrey \& Leicht, 2013). At present, wheelchair rugby players are classified into one of seven classification groups based on their impairment, ranging from 0.5 (most impaired) to 3.5 (least impaired). Each team is permitted to field four players at any one time, whereby the total number of points cannot exceed 8.0 points (Molik et al., 2008) with continuous roll-on substitutions permitted. scientific attention (Molik et al., 2008; Morgulec-Adamowicz et al., 2010; Rhodes, Mason, Perrat, Smith, \& Goosey-Tolfrey, 2014a; Rhodes et al., 2014b; Sarro, Misuta, Burkett, Malone, \& Barros, 2010). Early notational analysis data suggested that 'high-point' players (2.0-3.5 classification group) generally perform better than 'low-point' players (0.5-1.5 classification group) in most of the ball-handling match activities such as points scored, interceptions, passes made and passes caught (Molik et al., 2008; Morgulec-Adamowicz et al., 2010). The close relationship between classification and on-court role may partially explain such findings. Low-point players typically possess limited shoulder and wrist stability that impede ball-handling capabilities as well as reduce wheelchair manoeuvrability skills, restricting players to defensive on-court roles (Molik et al., 2008). Alternatively, high-point players generally display good shoulder and wrist stability, enabling players to perform ballhandling tasks and wheelchair handling skills effectively, which sees them occupy offensive on-court roles (IWRF, 2014). Through recent developments in technology (Rhodes et al., 2014a), information regarding the activity profiles during wheelchair rugby match-play have been described. During competition, elite wheelchair rugby players typically cover distances between 3500-4600 m (Rhodes et al., 2014b; Sarro, et al., 2010), with an average peak speed of $3.48 \pm 0.36 \mathrm{~m} \cdot \mathrm{s}^{-1}$ (Rhodes et al., 2014b). Match-play has been further characterised by prolonged low-intensity activities ( $\leq 50 \%$ peak speed) interspersed with frequent periods of 
1 trends in match performance were further highlighted; whereby greater total distance, mean 2 speed (Sarro et al., 2010) and peak speed values (Rhodes et al., 2014b) were reported as 3 classification group increased. Furthermore, when grouped by on-court role, notable trends in 4 the intensity of match-play activity were also evident (Rhodes et al., 2014b). Specifically, 5 defensive players spent a significantly greater amount of time performing very low speed activities compared to offensive players, whilst, a greater number of high-intensity bouts were exhibited by defensive players ( 13) compared to offensive players ( 9) (Rhodes et al., 8 2014b). Such results may be attributed to the key requirements for the varying on-court roles. 9 These roles require defensive players to block and trap opponents resulting in longer durations of very low speed activity, yet must perform high-intensity activities more frequently to compete with more functionally able opponents. However, an understanding of which aspects of mobility are associated with successful performance is required to further future monitoring in the training environment.

Whilst key indicators of successful performance have been explored using team rank in able-bodied sports, no such information exists for wheelchair rugby. In the only study to investigate the influence of successful performance within an elite wheelchair sporting application, greater peak speeds were reported in high-ranked wheelchair tennis players (Sindall et al., 2013). While high peak speeds may be advantageous for wheelchair tennis performance, it is important to acknowledge the classification and tactical roles associated with individuals in wheelchair rugby that could influence this relationship. Therefore the aim of the current study was to establish which aspects of mobility were associated with successful performance as determined by team rank during elite wheelchair rugby. A secondary aim was to determine whether the impact of mobility on performance was further influenced by classification.

\section{Methods}

\section{Participants}

27 All National teams competing in the 2013 European and Americas Zonal Championships were invited to participate in the current study. Out of the 15 competing teams, 11 agreed to participate giving a sample of 111 elite International wheelchair rugby players (male: $n=110$; female: $n=1$; age: $32 \pm 7$ years). Similar to previous investigations (Di Salvo et al., 2009;

31 Rampinini et al., 2007), players were subdivided into the following three groups according to 
1 their teams International Wheelchair Rugby Federation (IWRF) ranking prior to the start of 2 both competitions: the top 3 ranked teams (HIGH); middle 5 ranked teams (MID); and the 3 lowest 3 ranked teams (LOW). Team ranking was taken prior to the start of both competitions 4 based on recommendations made by previous research (Castellano et al., 2014) and did not

5 change between competitions. Each player was assigned into one of four groups according to 6 their IWRF classification (Morgulec-Adamowicz et al., 2010; Rhodes et al., 2014b), 7 defensive players were categorised as groups I (0.5) and II (1.0-1.5), whilst offensive players 8 as groups III (2.0-2.5) and IV (3.0-3.5). Approval for the study was obtained from the IWRF 9 and the organising committee of each tournament in addition to the University's local ethical advisory committee. All participants provided their written informed consent to participate in the current investigation.

\section{Equipment}

13 Data were collected during all matches using a radio-frequency based indoor tracking system 14 (8 Hz; Ubisense, Cambridge, UK) as previously described and validated by Rhodes et al. 15 (2014a). When assessing total distance during a simulated match quarter (999 $\pm 65 \mathrm{~m}$ ), the 16 indoor tracking system reported a relative error of $<0.2 \%$ compared against a total laser 17 station as the criterion measure. Furthermore, a mean systematic error of $0.05 \mathrm{~m} \cdot \mathrm{s}^{-1}$ for measuring peak speed was reported during linear sprints in excess of $4.00 \mathrm{~m} \cdot \mathrm{s}^{-1}$. Each player was equipped with a small, lightweight tag ( $\operatorname{size}=40 \times 40 \times 10 \mathrm{~mm}$; mass $=25 \mathrm{~g}$ ), positioned on or near the foot-strap of the players rugby wheelchair. All players were familiarised with the tag locations during training sessions and practice matches prior to the start of the competitions.

\section{Experimental design}

24 The indoor tracking system was installed on the main court of each tournament venue and 25 data were collected from a total of 30 matches. Each participating team was monitored 26 whenever they played on the main court (minimum of 3 matches, range 3-6), with data collected during pool $(n=20)$, crossover $(n=4)$ and placement $(n=6)$ matches. Each match involving a participating team was included for data collection with each team member equipped with a radio-frequency tag. Up to 24 players (12 players from each team) wore a tag during any given match, with a match observation characterised for each individual by the accumulation of activity collected during the respective four quarters of that match (353 
1 match observations). Activity profiles were then presented as the mean of all match 2 observations as grouped by each individuals team rank and classification. Match activity has 3 previously been shown not to deviate across quarters over multiple wheelchair rugby matches 4 (Rhodes et al., 2014b). Additionally, as continuous roll-on substitutions are common features 5 of match-play, observations from substituted players were also included for analysis. 6 Collection was only paused during any periods of extended stoppages (time-outs, equipment 7 calls etc.) since players also remain active during the stopped game clock (Sarro et al., 2010).

Relative distance covered ( $\mathrm{m} \cdot \mathrm{min}^{-1}$; relative to time spent on court), mean and peak speed $\left(\mathrm{m} \cdot \mathrm{s}^{-1}\right)$ was determined for each player during each match observation. Relative time was quantified into five classification-specific arbitrary speed zones (Table 1) as previously used in wheelchair rugby (Rhodes et al., 2014b). The speed zones were based upon the percentage of the mean peak speed attained for each classification group across multiple matches (Rhodes et al., 2014b). The percentage thresholds, as previously used in team sports

14 (Cahill, Lamb, Worsfold, Headey, \& Murray, 2013), were: very low ( $\leq 20 \%)$, low (21-50\%), moderate (51-80\%), high (81-95\%) and very high (> 95\%). High-intensity activities consisted of the combined time spent in high and very high speed zones and were extended to include the relative number of high-intensity activities performed and both the mean and max duration and distance of these activities.

\section{Statistical Analyses}

Data analysis was performed using the Statistical Package for the Social Sciences (SPSS version 21, Chicago, IL). Descriptive statistics (mean \pm standard deviation [SD]) were calculated for each participant for all activity profiles. Normality and homogeneity of variance was confirmed by Shapiro-Wilk and Levene's tests respectively. Since players differed in the number of match observations they participated in and the varying sample sizes between team ranks and classification groups, mixed linear modelling was applied to account for the unbalanced design (Cnaan, Laird \& Slasor, 1997). Main effects and interactions were accepted as statistically significant whereby $P \leq 0.05$. Pairwise comparisons were utilised to explore any significant interactions between team ranks and classification groups, with 95\% confidence intervals (95\% CI) for differences also presented. Effect sizes (ES) were calculated as the ratio of the mean difference to the pooled standard deviation of the difference. The magnitude of the effect sizes were classed as trivial $(<0.2)$, small $(0.2-$ 
1 0.6), moderate (0.6-1.2), large (1.2-2.0), and very large ( $\geq 2.0)$ based on previous guidelines

2 (Batterham \& Hopkins, 2006).

\section{Results}

4 No significant effect of team rank was observed for relative distance (Figure 1a; $P=0.532$ ) and mean speed (Figure 1b; $P=0.538$ ). However, there was a significant difference between mean playing time (mm:ss) and team rank $(P \leq 0.0005)$, which was significantly reduced in LOW (34:51 \pm 8:35) compared to MID (48:54 \pm 0:51; $P \leq 0.0005 ; 95 \%$ CI $=-245.7$ to -157.8 ; $\mathrm{ES}=1.7)$ and HIGH $(45: 38 \pm 9: 53 ; P \leq 0.0005 ; 95 \% \mathrm{CI}=-136.1$ to $-44.0 ; \mathrm{ES}=1.2)$. The number of substitutions performed was also shown to be influenced by team rank $(P \leq$ 0.0005). LOW performed a greater number of substitutions per match (12 \pm 4$)$ than both MID $(4 \pm 3 ; P \leq 0.0005 ; 95 \% \mathrm{CI}=4.7$ to 10.6 ; $\mathrm{ES}>2.0)$ and $\mathrm{HIGH}(5 \pm 3 ; P \leq 0.0005 ; 95 \% \mathrm{CI}=$ 2.9 to $9.8 ; \mathrm{ES}=1.7)$.

Peak speed was significantly affected by team rank $(P=0.002)$. As illustrated in Figure 1c, HIGH achieved greater peak speeds (3.56 $\left.\pm 0.40 \mathrm{~m} \cdot \mathrm{s}^{-1}\right)$ compared to LOW (3.27 \pm $0.42 \mathrm{~m} \cdot \mathrm{s}^{-1} ; P \leq 0.0005 ; 95 \% \mathrm{CI}=-0.4$ to $\left.-0.1 ; \mathrm{ES}=0.7\right)$ and $\operatorname{MID}\left(3.45 \pm 0.41 \mathrm{~m} \cdot \mathrm{s}^{-1} ; P=\right.$ 0.003 ; $95 \% \mathrm{CI}=0.1$ to 0.2 ; $\mathrm{ES}=0.3$ ). The relative time spent within low, high and very high speed zones were also significantly influenced by team rank $(P \leq 0.0005)$. Figure 2 reveals LOW (52.3 $\pm 7.0 \%)$ spent more time in the low speed zone compared to MID (46.7 $\pm 7.9 \%$; $P \leq 0.0005 ; 95 \% \mathrm{CI}=3.0$ to $8.1 ; \mathrm{ES}=0.7)$ and $\mathrm{HIGH}(46.8 \pm 7.6 \% ; P \leq 0.0005 ; 95 \% \mathrm{CI}=$ 2.9 to 8.1 ; ES $=0.8)$. However, HIGH spent greater time within high $(2.9 \pm 1.6 \%)$ and very high $(0.7 \pm 0.8 \%)$ speed zones compared to LOW $(1.5 \pm 1.1 \%$ and $0 \pm 0.4 \%$; $P \leq 0.0005$; ES $=0.9-1.0)$ and $\mathrm{MID}(2.0 \pm 1.3 \%$ and $0.3 \pm 0.5 \% ; P \leq 0.025 ; \mathrm{ES}=0.6)$. High-intensity activities were also significantly influenced by team rank $(P \leq 0.0005)$. As shown in Table 2 , HIGH performed a greater number of relative high-intensity activities compared to LOW ( $P$ $\leq 0.0005 ; 95 \% \mathrm{CI}=-0.5$ to $-0.2 ; \mathrm{ES}=1.4)$ and $\mathrm{MID}(P=0.006 ; 95 \% \mathrm{CI}=-0.3$ to $-0.04 ; \mathrm{ES}=$ 0.8). Whilst HIGH also covered greater mean $(P \leq 0.001$; ES $=0.5-0.8)$ and max distances $(P$ $\leq 0.006$; $\mathrm{ES}=0.6-1.1)$, for a longer mean $(P \leq 0.0005$; $\mathrm{ES}=0.8-1.0)$ and max duration $(P \leq$ 0.008; ES = 0.5-1.1) at high-intensities compared to both LOW and MID. 
No significant interaction was observed between team rank and classification group

2 for relative distance ( $P=0.141)$ or mean speed $(P=0.102)$. However, classification group was shown to influence peak speed values across team rank $(P=0.008)$. Table 3 reveals HIGH achieved significantly greater peak speeds compared to LOW across all classification groups $(P \leq 0.001$; ES $=0.6-1.5)$, whilst HIGH groups III and IV players achieved greater peak speeds compared to respective MID players $(P \leq 0.005$; ES $=0.7-0.8)$. A significant interaction was observed across low $(P=0.009)$, high $(P \leq 0.0005)$ and very high $(P \leq$ 0.0005) speed zones, whilst a significant interaction also existed for the high-intensity activities performed during match-play $(P \leq 0.0005)$. Post hoc analyses revealed:

- Group I: LOW players spent significantly greater time within the low speed zone compared to $\mathrm{MID}(P \leq 0.0005 ; 95 \% \mathrm{CI}=3.0$ to 12.3 ; ES $=1.4)$ and $\mathrm{HIGH}(P \leq$ less time in the high $(P \leq 0.0005 ; \mathrm{ES}=1.0-1.3)$ and very high speed zones $(P \leq 0.029$; ES = 1.1-1.4) compared to HIGH. LOW displayed a significant difference with HIGH for all high-intensity activities ( $P \leq 0.005$; $\mathrm{ES}=1.0-1.5$ ), whilst the relative number $(P=0.002 ; 95 \% \mathrm{CI}=-0.5$ to $-0.1 ; \mathrm{ES}=0.7)$, max distance $(P=0.027 ; 95 \% \mathrm{CI}=-7.8$ to -0.9 ; $\mathrm{ES}=0.9)$ and max duration $(P=0.038 ; 95 \% \mathrm{CI}=0.5$ to 1.8 ; $\mathrm{ES}=0.9)$ of high-intensity activities significantly differed between LOW and MID. MID performed significantly less high-intensity activities compared to HIGH ( $P \leq 0.008$; $\mathrm{ES}=0.6-1.0)$.

- Group II: LOW players spent significantly less time in high and very high speed zones as opposed to $\mathrm{MID}(P=0.006$; ES $=0.6-0.8)$ and HIGH $(P=0.07$; $\mathrm{ES}=0.8-$ 1.0), whilst MID spent significantly less time in the high speed zone than HIGH ( $P=$ 0.003 ; $95 \% \mathrm{CI}=0.3$ to 1.3 ; $\mathrm{ES}=0.5$ ). LOW were shown to perform significantly less relative number of high-intensity activities compared to $\operatorname{MID}(P=0.004 ; 95 \% \mathrm{CI}=$ 0.7 to -0.1 ; $\mathrm{ES}=1.1)$ and $\mathrm{HIGH}(P \leq 0.0005 ; 95 \% \mathrm{CI}=-0.9$ to $-0.3 ; \mathrm{ES}=1.7)$.

- Group III: LOW and MID players were found to spend significantly less time in high $(P \leq 0.023 ; \mathrm{ES}=0.7-0.8)$ and very high speed zones $(P \leq 0.026$; ES $=1.1-1.2)$ as opposed to HIGH. All parameters of high-intensity activities were also shown to be significantly lower in LOW $(P \leq 0.001$; ES $=0.5-0.8)$ and $\mathrm{MID}(P \leq 0.006$; $\mathrm{ES}=0.4-$ 0.8) compared to HIGH.

- Group IV: MID were shown to spend significantly less time within high speed zones $(P=0.022 ; 95 \% \mathrm{CI}=0.2$ to $2.0 ; \mathrm{ES}=0.9)$ compared to HIGH. Although the relative 
number of high-intensity activities did not differ between team ranks ( $P \geq 0.174$; ES $\leq$ $0.2)$, LOW and MID were found to cover less mean $(P \leq 0.0005$; ES $=1.1-2.0)$ and max distances $(P \leq 0.001$; ES $=1.0-2.0)$, for lower mean $(P \leq 0.0005$; $\mathrm{ES}=1.3-2.0)$ and max durations at high-intensities $(P \leq 0.001$; ES $=1.0-2.0)$ compared to HIGH.

$* * *$ INSERT TABLE $3 * * *$

\section{Discussion}

The current study was the first to examine the influence of team rank on the activity profiles of elite wheelchair rugby players during competition to establish which aspects of mobility are critical to successful performance. Although the volume of activity was largely uninfluenced by team rank, peak speeds and the capacity to perform at high-intensities were both found to be associated with successful performance in wheelchair rugby. Activity profiles were further influenced by classification and on-court role, as demonstrated by the significantly higher peak speed values observed for HIGH offensive players (2.0-3.5). Highintensity activities were also shown to be important and classification-dependant, with greater time spent within very high speed zones observed in HIGH group I and offensive players. Such results demonstrate which aspects of mobility performance were most associated with successful performance in wheelchair rugby, which may have implications on future training prescription and performance monitoring.

The current study revealed large differences in playing time between team ranks. The shorter playing time of LOW suggests that players lack the physical capacity to maintain performance over prolonged durations, which was further supported by the greater number of substitutions performed by LOW. Consequently, coaching strategies designed to maximise physical capacity may improve the match performance of lower-ranked teams. Nevertheless, the relative distance covered, along with mean speed were not significantly different between MID and HIGH. Therefore, it appeared that successful performance in wheelchair rugby was not influenced by the volume of activity performed. Even when categorised by classification, the volume of activity performed was largely unaffected by team rank. The comparable activity volume of all players across team ranks reported here suggests association to successful performance is negligible. Despite this, the performance of Paralympic courtbased sport players has previously been shown to be highly dependent upon aerobic fitness (Bernardi et al., 2010). Therefore, elite wheelchair rugby players should be sufficiently 
1 prepared so that they can meet the activity demands (3500-4600 m) required for competition 2 (Rhodes et al., 2014b; Sarro et al., 2010).

Since opponents can dictate a player's movement on-court, it was anticipated that the ability to frequently reach high speeds and sustain high-intensity activities would be restricted. Previous research has suggested that sprinting performance and the ability to reach high peak speeds to be less of a priority in wheelchair rugby compared to acceleration and manoeuvrability performance (Mason, Porcellato, van der Woude, \& Goosey-Tolfrey, 2010). That said, our study found HIGH achieved greater peak speeds (3.59 $\left.\pm 0.44 \mathrm{~m} \cdot \mathrm{s}^{-1}\right)$ than both LOW $\left(3.31 \pm 0.49 \mathrm{~m} \cdot \mathrm{s}^{-1}\right)$ and MID $\left(3.46 \pm 0.43 \mathrm{~m} \cdot \mathrm{s}^{-1}\right)$. This supports and extends previous knowledge gleaned from wheelchair tennis (Sindall et al., 2013). Furthermore, although the majority of activity during wheelchair rugby is spent at low-intensities ( 75\%) (Rhodes et al., 2014b), the current study established that players from HIGH spent a greater proportion of time performing high-intensity activities compared to players from lower ranked teams. One likely explanation that is difficult to quantify from the current data is that HIGH prevented the opposition from achieving high peak speeds and sustaining high-intensity activities by adopting full-court press tactics. Such tactics work by pressurising the ball-handler and reducing the on-court space using 'trapping' techniques (Malone \& Orr, 2010). On the other hand, it is possible that HIGH players may be more capable of creating court space in-order to perform higher peak speeds and a greater number of high-intensity activities. Although team efficiency and playing style may account for some differences between team ranks, future notational analysis techniques are required to establish this information with regard to positional transitions, ball possession, and court zones etc. Nevertheless the current findings reveal that success in wheelchair rugby can be characterised by a player's ability to consistently reach high peak speeds, whilst performing at high-intensities and therefore training and game-patterns should be structured to promote this.

Our findings were able to distinguish differences between offensive and defensive roles and highlight the increased importance of peak speed for offensive players. As such, HIGH offensive players achieved greater peak speeds than MID offensive players, whilst no differences existed between MID and HIGH defensive players. Previous research has demonstrated that the majority of points ( 88\%) are scored by offensive players in wheelchair rugby (Molik et al., 2008; Morgulec-Adamowicz et al., 2010). Subsequently the capacity to achieve superior peak speeds could prove pivotal to perform this role effectively and influence team success. Alternatively, peak speed may be less important for defensive 
1 players, whereby tactical aspects of performance may be more of a necessity. This could be associated with differences in equipment between roles, whereby defensive players typically use a wheelchair with a substantial rear-wheel camber (Keogh, 2011). While a greater camber increases their stability and blocking ability, this comes at the expense of peak speed (Faupin Campillo, Weissland, Gorce, \& Thevenon, 2004; Mason, Woude, Tolfrey, \& Goosey-Tolfrey, 2011). Such findings therefore further reiterate the need for role-specific training (Rhodes et al., 2014b) and also identify this parameter as one of the key performance indicators for talent identification purposes.

The magnitude of differences in high-intensity activities was found to be classification-dependant, whereby HIGH group I and offensive players spent significantly greater time within very high speed zones and were able to sustain these activities for longer compared to respective MID players. It could be suggested that players at the highest level of wheelchair rugby have the physical capacity to maintain repeated high-intensity activities during match-play. Additionally, it is plausible that like peak speeds, HIGH players are more capable of finding court space in-order to maintain repeated high-intensity activities. Subsequently, training strategies aimed at sustaining high-intensity activities under the pressure of opponents may be beneficial for offensive players. Alternatively, the time spent within the very high speed zone and the ability to sustain high-intensity activities were not shown to differ in group II players between MID and HIGH. Subsequently, given that previous research identified no differences in ball-handling patterns between groups I and II (Morgulec-Adamowicz et al., 2010), such results may imply that the mobility characteristics of group I players could be more critical to successful team performance than group II players, whilst subsequently reducing the total on-court classification points (8.0 points permitted at any one time). Nevertheless, a technical analysis of wheelchair rugby is further required to supplement the activity profiles currently presented to gain a holistic appraisal of the sport.

Team line-up is an additional factor that may influence the activity profiles during match-play. The current data would suggest LOW and HIGH teams generally utilised group III players, as opposed to MID teams that typically employed more group II and IV players during match-play. It is recommended however that future research investigates the effect of different line-up strategies (i.e. mid-point vs. high- and low-point line-ups) on activity profiles and performance in wheelchair rugby. In elite athletes with tetraplegia, peak heart 
1 rate response is generally reduced (Goosey-Tolfrey \& Leicht, 2013), consequently the

2 collection of heart rate in wheelchair rugby players is therefore questionable and methods

3 such as rating of perceived exertion (RPE) may be better advocated. Despite this, a limitation

4 of the current study was the inability to examine the individual physiological responses in 5 relation to the determination of speed zones. Future work utilising individualised 6 physiological measures (e.g. blood lactate) alongside the traditional arbitrary approach is 7 recommended (Hunter et al., 2014). Nevertheless, normalising speed zones based on match8 play sprinting capacity may reflect an ecologically valid approach to between-player and rank 9 comparisons. Moreover, the categorising of movement into speed zones could further be used 10 to identify individual work:rest ratios. Such information would provide coaches with 11 important information that could implemented into future training strategies and is 12 subsequently worthy of further investigation. Finally, although high-intensity activities were 13 deemed an important indicator of performance in wheelchair rugby, a limitation with the 14 current study is that the indoor tracking system used cannot quantify acceleration 15 performance due to the restricted sampling frequency. Therefore future research would 16 benefit from the incorporation of accelerometry to provide a more in-depth insight into high17 intensity activities, which may occur at low speeds, in wheelchair rugby.

\section{Conclusion}

19 The data provide new insights into the possible influence of successful performance on 20 activity profiles and highlights the impact of classification. The capacity to reach higher peak speeds and to perform increased activities at high-intensities was associated with successful performance in wheelchair rugby. These variables were further influenced by classification, specifically in group I and offensive players (groups III \& IV). Although the volume of

24 activity appeared uninfluenced by team rank, player conditioning appeared important since 25 LOW performed more substitutions and consequently averaged shorter playing durations. 
2 Batterham, A., \& Hopkins, W. (2006). Making meaningful inferences about magnitudes.

3 International Journal of Sports Physiology and Performance, 1, 50-57.

4 Bernardi, M., Guerra, E., Di Giacinto, B. Di Cesare, A. Castellano, V., \& Bhambhani Y.

5 (2010). Field evaluation of Paralympic athletes in selected sports: implications for training.

6 Medicine and Science in Sports and Exercise, 42, 1200-1208.

7 Cahill, N., Lamb, K., Worsfold, P., Headey, R., \& Murray, S. (2013). The movement

8 characteristics of English Premiership rugby union players. Journal of Sports Sciences, 31,

9 229-237.

10 Castellano, J., Alvarez, D., \& Bradley, P. (2014). Evaluation of research using computerized

11 tracking systems (Amisco and Prozone) to analyse physical performance in elite soccer: a

12 systematic review. Sports Medicine, 44, 701-712.

13 Cnaan, A., Laird, N.M., \& Slasor, P. (1997). Using the general linear mixed model to analyse

14 unbalanced repeated measures and longitudinal data. Statistics in Medicine, 16, 2349-2380.

15 Faupin, A., Campillo, P., Weissland, T., Gorce, P., \& Thevenon, A. (2004) The effects of

16 rear-wheel camber on the mechanical parameters produced during wheelchair sprinting of

17 handibasketball athletes. Journal of rehabilitation research and development, 41, 421-428.

18 Goosey-Tolfrey, V.L., \& Leicht, C.A. (2013). Field-based physiological testing of wheelchair

19 athletes. Sports Medicine, 43, 77-91.

20 Hunter, F., Bray, J., Towlson, C., Smith, M., Barrett, S., Madden, J., Abt, G., \& Lovell, R.

21 (2014). Individualisation of time-motion analysis: a method comparison and case report

22 series. International Journal of Sports Medicine, [Epub ahead of print].

23 International Wheelchair Rugby Federation. IWRF (online). http://www.iwrf.com. Accessed

241 Nov 2014.

Keogh, J.L. (2011) Paralympic sport: an emerging area for research and consultancy in sports biomechanics. Sports Biomechanics, 10, 234-253.

27 Mason, B.S., Porcellato, L., van der Woude, L.H., \& Goosey-Tolfrey, V.L. (2010). A

28 qualitative examination of wheelchair configuration for optimal mobility performance in

29 wheelchair sports: A pilot study. Journal of Rehabilitation Medicine, 42, 141-149.

30 Mason, B.S., van der Woude, L.H., Tolfrey, K., \& Goosey-Tolfrey, V.L. (2011). The effects 31 of rear-wheel camber on maximal effort mobility performance in wheelchair athletes.

32 International Journal of Sports Medicine, 33, 199-204.

33 Molik, B., Lubelska, E., Kosmol, A., Bogdan, M., Yilla, A., \& Hyla, E. (2008). An

34 examination of the international wheelchair rugby federation classification system utilizing 35 parameters of offensive game efficiency. Adapted Physical Activity Quarterly, 25, 335-351. 
1 Morgulec-Adamowicz, N., Kosmol, A., Bogdan, M., Molik, B., Rutkowska, I., \&

2 Bednarczuk, G. (2010). Game efficiency of wheelchair rugby athletes at the 2008 Paralympic

3 Games with regard to player classification. Human Movement, 11, 29-36.

4 Rhodes, J.M., Mason, B.S., Perrat, B., Smith, M., \& Goosey-Tolfrey, V.L. (2014a). The

5 validity and reliability of a novel indoor player tracking system for use within wheelchair

6 court sports. Journal of Sports Sciences, 32, 1639-1647.

7 Rhodes, J.M., Mason, B.S., Perrat, B., Smith, M., Malone, L.A., \& Goosey-Tolfrey, V.L.

8 (2014b). Activity profiles of elite wheelchair rugby players during competition. International

9 Journal of Sports Physiology and Performance, [Epub ahead of print.]

10 Sarro, K.J., Misuta, M.S., Burkett, B., Malone, L.A., \& Barros, R.M.L. (2010). Tracking of

11 wheelchair rugby players in the 2008 demolition derby final. Journal of Sports Sciences, 28,

12 193-200.

13 Sindall, P., Lenton, J.P., Tolfrey, K., Cooper, R.A., Oyster, M., \& Goosey-Tolfrey, V.L.

14 (2013). Wheelchair tennis match-play demands: Effect of player rank and result.

15 International Journal of Sports Physiology and Performance, 8, 28-37. 


\section{Figure Legends}

2 Figure 1. Relative distance (a), mean speed (b), and peak speed (c) in relation to team rank 3 during match-play. Data presented as means \pm SD. *Significantly different to MID. $4 \quad$ \#Significantly different to HIGH.

5 Figure 2. Match intensity in relation to team rank during a typical match. Data presented as 6 means \pm SD. *Significantly different to MID. "Significantly different to HIGH. 
Table 1. Classification-specific arbitrary speed zones $\left(\mathrm{m} \cdot \mathrm{s}^{-1}\right)$ previously proposed for wheelchair rugby

\begin{tabular}{|c|c|c|c|c|}
\hline & \multicolumn{4}{|c|}{ Classification group } \\
\hline & $\mathbf{I}$ & II & III & IV \\
\hline Very low & $\leq 0.60$ & $\leq 0.69$ & $\leq 0.73$ & $\leq 0.76$ \\
\hline Low & $0.61-1.50$ & $0.70-1.72$ & $0.74-1.84$ & $0.77-1.91$ \\
\hline Moderate & $1.51-2.39$ & $1.73-2.75$ & $1.85-2.94$ & $1.92-3.06$ \\
\hline High & $2.40-2.84$ & $2.76-3.27$ & $2.95-3.49$ & $3.07-3.63$ \\
\hline Very High & $>2.84$ & $>3.27$ & $>3.49$ & $>3.63$ \\
\hline
\end{tabular}

Classification groups: $\mathrm{I}=0.5 ; \mathrm{II}=1.0-1.5 ; \mathrm{III}=2.0-2.5 ; \mathrm{IV}=3.0-3.5$.

Table 2. High-intensity activities (mean \pm SD) during a typical wheelchair rugby match in relation to team rank

\begin{tabular}{|c|c|c|c|c|}
\hline & & & Team Rank & \\
\hline & & $\begin{array}{c}\text { LOW } \\
(n=79)\end{array}$ & $\begin{array}{c}\text { MID } \\
(n=145)\end{array}$ & $\begin{array}{c}\text { HIGH } \\
(n=129)\end{array}$ \\
\hline \multirow{5}{*}{$\begin{array}{l}\text { High-intensity } \\
\text { Activities }\end{array}$} & Relative Number $(n)$ & $0.4 \pm 0.3^{* \#}$ & $0.6 \pm 0.4^{\#}$ & $0.9 \pm 0.4$ \\
\hline & Mean Distance (m) & $4.5 \pm 2.8^{\#}$ & $5.3 \pm 2.6^{\#}$ & $6.7 \pm 2.7$ \\
\hline & Max Distance (m) & $7.7 \pm 5.2^{* \#}$ & $11.3 \pm 5.7^{\#}$ & $14.1 \pm 6.1$ \\
\hline & Mean Duration (s) & $1.4 \pm 0.8^{\#}$ & $1.6 \pm 0.8^{\#}$ & $2.2 \pm 0.8$ \\
\hline & Max Duration (s) & $2.4 \pm 1.6^{* \#}$ & $3.4 \pm 1.7^{\#}$ & $4.2 \pm 1.8$ \\
\hline
\end{tabular}

$n=$ number of match observations. *Significantly different to MID. ${ }^{\#}$ Significantly different to HIGH. 
Table 3. Activity profiles during a typical wheelchair rugby match categorised by team rank and classification

\begin{tabular}{|c|c|c|c|c|c|c|c|c|c|c|c|c|}
\hline & \multicolumn{12}{|c|}{ Team Rank } \\
\hline & \multicolumn{4}{|c|}{ LOW } & \multicolumn{4}{|c|}{ MID } & \multicolumn{4}{|c|}{ HIGH } \\
\hline & \multicolumn{2}{|c|}{ Defensive } & \multicolumn{2}{|c|}{ Offensive } & \multicolumn{2}{|c|}{ Defensive } & \multicolumn{2}{|c|}{ Offensive } & \multicolumn{2}{|c|}{ Defensive } & \multicolumn{2}{|c|}{ Offensive } \\
\hline & $\begin{array}{c}\mathrm{I} \\
(n=13)\end{array}$ & $\begin{array}{c}\text { II } \\
(n=13)\end{array}$ & $\begin{array}{c}\text { III } \\
(n=42)\end{array}$ & $\begin{array}{c}\mathrm{IV} \\
(n=11)\end{array}$ & $\begin{array}{c}\mathrm{I} \\
(n=22)\end{array}$ & $\begin{array}{c}\text { II } \\
(n=53)\end{array}$ & $\begin{array}{c}\text { III } \\
(n=24)\end{array}$ & $\begin{array}{c}\text { IV } \\
(n=46)\end{array}$ & $\begin{array}{c}I \\
(n=23)\end{array}$ & $\begin{array}{c}\text { II } \\
(n=24)\end{array}$ & $\begin{array}{c}\text { III } \\
(n=68)\end{array}$ & $\begin{array}{c}\text { IV } \\
(n=14)\end{array}$ \\
\hline $\begin{array}{l}\text { Relative Distance } \\
\left(\mathrm{m} \cdot \mathrm{min}^{-1}\right)\end{array}$ & $60.1 \pm 5.2$ & $66.0 \pm 3.9$ & $74.9 \pm 15.0$ & $80.6 \pm 11.4$ & $59.0 \pm 8.1$ & $69.1 \pm 8.1$ & $77.4 \pm 7.5$ & $76.4 \pm 10.4$ & $63.2 \pm 6.9$ & $71.7 \pm 14.2$ & $76.8 \pm 8.2$ & $81.3 \pm 6.4$ \\
\hline Mean Speed $\left(\mathrm{m} \cdot \mathrm{s}^{-1}\right)$ & $1.00 \pm 0.09$ & $1.10 \pm 0.07$ & $1.25 \pm 0.25$ & $1.34 \pm 0.19$ & $0.98 \pm 0.13$ & $1.15 \pm 0.14$ & $1.29 \pm 0.12$ & $1.28 \pm 0.17$ & $1.05 \pm 0.12$ & $1.17 \pm 0.21$ & $1.26 \pm 0.14$ & $1.35 \pm 0.11$ \\
\hline Peak Speed $\left(\mathrm{m} \cdot \mathrm{s}^{-1}\right)$ & $2.60 \pm 0.15^{* \#}$ & $3.13 \pm 0.27^{\#}$ & $3.45 \pm 0.30^{\#}$ & $3.57 \pm 0.25^{* \#}$ & $2.91 \pm 0.26$ & $3.36 \pm 0.35$ & $3.51 \pm 0.22^{\#}$ & $3.73 \pm 0.35^{\#}$ & $3.08 \pm 0.25$ & $3.45 \pm 0.30$ & $3.70 \pm 0.32$ & $3.92 \pm 0.26$ \\
\hline Very Low (\%) & $33.3 \pm 8.0$ & $36.0 \pm 5.7$ & $30.0 \pm 8.6$ & $27.2 \pm 13.2$ & $35.7 \pm 9.6$ & $34.6 \pm 9.3$ & $26.9 \pm 7.5$ & $31.1 \pm 11.8$ & $33.7 \pm 6.5$ & $34.7 \pm 12.1$ & $29.7 \pm 8.5$ & $28.5 \pm 4.7$ \\
\hline Low (\%) & $48.2 \pm 5.5^{\text {*\# }}$ & $46.2 \pm 5.5$ & $55.0 \pm 6.7$ & $53.1 \pm 7.7$ & $40.6 \pm 5.7$ & $43.9 \pm 9.3$ & $52.4 \pm 6.2$ & $50.5 \pm 7.1$ & $41.6 \pm 4.9$ & $40.4 \pm 7.1$ & $49.6 \pm 6.5$ & $52.7 \pm 4.8$ \\
\hline Moderate (\%) & $20.0 \pm 4.1$ & $18.5 \pm 4.1$ & $17.6 \pm 4.1$ & $19.9 \pm 7.6$ & $20.4 \pm 4.4$ & $21.0 \pm 3.6$ & $20.6 \pm 4.6$ & $18.2 \pm 4.5$ & $21.2 \pm 5.1$ & $21.5 \pm 7.3$ & $18.9 \pm 4.4$ & $18.4 \pm 3.5$ \\
\hline High (\%) & $1.5 \pm 1.3^{\#}$ & $1.1 \pm 0.9^{* \#}$ & $1.6 \pm 1.0^{\#}$ & $2.2 \pm 2.1$ & $2.6 \pm 1.8^{\#}$ & $2.1 \pm 1.2^{\#}$ & $1.6 \pm 0.8^{\#}$ & $1.9 \pm 1.2^{\#}$ & $4.1 \pm 1.9$ & $3.0 \pm 1.8$ & $2.5 \pm 1.3$ & $3.0 \pm 1.2$ \\
\hline Very High (\%) & $0.1 \pm 0.3^{\#}$ & $0.1 \pm 0.1^{* \#}$ & $0.3 \pm 0.2^{\#}$ & $0.5 \pm 0.1$ & $0.3 \pm 0.3^{\#}$ & $0.4 \pm 0.4$ & $0.2 \pm 0.1^{\#}$ & $0.4 \pm 0.5$ & $1.1 \pm 1.0$ & $0.6 \pm 0.7$ & $0.6 \pm 0.8$ & $0.7 \pm 0.5$ \\
\hline $\begin{array}{l}\text { Relative Number } \\
\left(\min ^{-1}\right)\end{array}$ & $0.3 \pm 0.3^{* \#}$ & $0.3 \pm 0.2^{* \#}$ & $0.4 \pm 0.3^{\#}$ & $0.6 \pm 0.5$ & $0.8 \pm 0.5^{\#}$ & $0.7 \pm 0.4$ & $0.5 \pm 0.2^{\#}$ & $0.6 \pm 0.4$ & $1.1 \pm 0.5$ & $1.0 \pm 0.5$ & $0.8 \pm 0.4$ & $0.7 \pm 0.2$ \\
\hline Mean Distance (m) & $3.3 \pm 2.5^{\#}$ & $4.0 \pm 3.2$ & $4.9 \pm 3.1^{\#}$ & $4.8 \pm 1.9^{\#}$ & $4.4 \pm 3.1^{\#}$ & $4.8 \pm 2.3$ & $5.2 \pm 2.0^{\#}$ & $6.1 \pm 2.9^{\#}$ & $6.5 \pm 2.1$ & $5.8 \pm 2.2$ & $6.5 \pm 3.1$ & $8.6 \pm 1.6$ \\
\hline Max Distance (m) & $5.1 \pm 3.8^{* \#}$ & $6.3 \pm 5.4$ & $8.7 \pm 5.5^{\#}$ & $8.9 \pm 4.1^{\#}$ & $8.9 \pm 4.3^{\#}$ & $11.6 \pm 5.9$ & $10.1 \pm 5.1^{\#}$ & $12.0 \pm 6.3^{\#}$ & $13.5 \pm 5.1$ & $13.5 \pm 5.8$ & $12.9 \pm 6.6$ & $17.2 \pm 4.3$ \\
\hline Mean Duration (s) & $1.3 \pm 0.9^{\#}$ & $1.3 \pm 1.0$ & $1.5 \pm 0.9^{\#}$ & $1.4 \pm 0.5^{\#}$ & $1.5 \pm 1.1^{\#}$ & $1.6 \pm 0.7$ & $1.5 \pm 0.6^{\#}$ & $1.7 \pm 0.8^{\#}$ & $2.4 \pm 0.8$ & $0.6 \pm 1.8$ & $1.9 \pm 1.0$ & $2.5 \pm 0.4$ \\
\hline Max Duration (s) & $1.9 \pm 1.3^{* *}$ & $2.0 \pm 1.7^{* \#}$ & $2.6 \pm 1.7^{\#}$ & $2.5 \pm 1.2^{\#}$ & $3.3 \pm 1.6^{\#}$ & $3.7 \pm 1.8$ & $2.9 \pm 1.5^{\#}$ & $3.4 \pm 1.7^{\#}$ & $4.6 \pm 1.7$ & $4.2 \pm 1.7$ & $3.8 \pm 2.0$ & $4.8 \pm 1.0$ \\
\hline
\end{tabular}

$n=$ number of match observations.

*Significantly different to MID. " Significantly different to HIGH. 